\title{
EDUCAÇÃO INDÍGENA E OS PROCESSOS DE ENSINO-APRENDIZAGEM ESCOLAR
}

\author{
Fernando Loureiro Luchetta* \\ Leonel Piovezana*
}

Resumo: O presente artigo é resultado de estudos sobre a educação indígena, considerando aspectos da educação formal escolar, tanto a utilização de métodos específicos e informais quanto a educação cultural da comunidade indígena de Nonoai (RS). As questões se fundamentam na verificação de: como se processa o desenvolvimento da educação no passar do tempo e como são organizadas as escolas a partir dos interesses socioculturais da comunidade indígena. Que métodos os pais Kaingang usavam para educar seus filhos antes da chegada na escola? O estudo fica facilitado, uma vez que como indígena e professor pesquisador o contato diário e de pertencimento facilitaram a construção do texto. Pudemos constatar que a fala na língua materna é o processo que melhor educa as crianças, pois essa é carregada de valores e exemplos de vida dos mais velhos. É pela língua materna que se aprende a valorização de ser kaingang e todo esse conhecimento é do encargo dos pais e esses representados pelos avôs, principais mestres da educação familiar Kaingang e afirmadores da cultura. A educação escolar, mesmo que nas tentativas de educar para a diversidade, especificidade, interculturalidade e bilinguismo, está longe de ser uma realidade. $\mathrm{Na}$ verdade, educa para a assimilação da cultura nacional da sociedade brasileira.

Palavras-chave: Kaingang. Educação. Escolar. Indígena. 


\title{
INDIGENUS EDUCATION AND THE TEACHI/ LEARNING PROCESS
}

\begin{abstract}
This article results of studies about the native education, considering aspects of the formal school education while the utilization of informal and specific approaches on the occasion of the cultural education of the native community of Nonoai (RS). The questions are substantiate in the verification of: how was prosecuted the development of the education in the course of time and how are arranged the schools starting from the sociocultural interests of the native community. What methods Kaingang's parentes used to educate his children before the arrival of school? The study is facilitated because as native and researcher professor the daily contact and of belonging facilitated the construction of the text. We established that speak in the first language is the trial that better educates the children, it is loaded with values and examples of life of older people. It is for the first language we learn to value of being Kaingang and all knowledge is job of the parents and those are represented by the grandmothers and grandfathers, main teachers of family education and affirming the Kaingang's culture. The school education, even though in the attempts of educate for the diversity, specificity, interculturality and bilinguism, is far from reality. In fact, educates to the assimilation of the national culture of the Brazilian society.
\end{abstract}

Keywords: Kaingang. Education. School. Native. 


\section{Introdução}

As crianças kaingang, ao chegar à escola, começam a receber os primeiros contatos com a educação formal. Esta educação formal começa na educação infantil e vai até a $3^{\text {a }}$ série, quando começam a ter contato com outros professores que trabalham na escola, com outras matérias. Nos anos seguintes, as crianças aprendem o Kaingang e a Língua Portuguesa, sendo que os professores têm um papel de reforçar o que seus pais já têm ensinado. Isso tudo implica considerar a dança e atitudes indígenas do dia a dia do índio. Esta educação vai até o $9^{\circ}$ ano.

$\mathrm{Na}$ escola indígena de Nonoai (RS), os alunos aprendem também a partir de outras disciplinas, fragmentadas, como Geografia, História, Matemática, Artes, Língua Inglesa, Educação Física, Ensino Religioso, Língua Portuguesa, além do Kaingang. Essas áreas do conhecimento são trabalhadas com os livros didáticos, mas implementados com as questões da comunidade e no estudo de suas fronteiras.

Com a história, além do livro, que é prático, se trabalha o passado do povo kaingang, sendo que isso se faz com cada disciplina que é trabalhada na escola. Consideramos que isso é ruim para os professores que trabalham com a língua materna, pois eles têm que fazer, preparar o material para trabalhar com seus alunos, pois não existe pronto.

A Escola Estadual Indígena de Ensino Fundamental Joaquim Gatem Cassemiro, no ano de 2012, contava com 11 professores, sendo que quatro trabalhavam com a língua materna. Desses professores, um só é habilitado para trabalhar com alunos de $5^{\circ}$ ano até o $9^{\circ}$ ano. Então, a educação formal e informal é complementa- 
da no dia a dia da comunidade Kaingang da Terra Indígena Nonoai, ressaltando as muitas dificuldades com a produção de material didático pedagógico e com a formação de professores, que tudo ainda é muito recente e as práticas da sociedade não indígena são muito presentes nos processos de ensino-aprendizagem. Constatamos que não está ainda concretizada uma educação específica e diferenciada para os povos indígenas dessa região.

Assim, nossos objetivos foram os de identificar as principais diretrizes da educação formal e informal na Aldeia Indígena de Nonoai (RS); compreender o processo de educação tradicional e informal no interior da Aldeia Indígena; identificar os conceitos e modo de educar na família indígena; analisar o processo do ensino formal na rede de educação oficial e tradicional na Aldeia Indígena de Nonoai (RS); e verificar os métodos empregados no ensino da escola indígena Joaquim Gatem Cassemiro.

Nossas perguntas e inquietações: como fazer educação formal diferenciada e específica, quando faltam professores habilitados e quando as escolas indígenas têm ainda de seguir calendários e formas segmentadas de ensino, conforme normas da sociedade não indígena?

Como a família e a escola podem contribuir para as práticas educativas formais e informais no processo ensino-aprendizagem da comunidade kaingang da aldeia de Nonoai (RS)?

Nosso estudo coloca no âmbito de discussões os processos educacionais diferenciados e questiona as formas de educação, sejam por professores indígenas, sejam por não indígenas. Verificamos as dificuldades dos professores índios e não índios, devido à falta de formação específica. Entre as dificuldades apresentadas, falta de material didático, principalmente para trabalhar o Kaingang, já que os professores que trabalham o idioma têm de fazer o próprio 
material e criar seus métodos de ensino, uma vez que as palavras e escritas Kaingang estão em plena construção e tradução.

Mas não é somente um problema do professor. Há outras dificuldades, uma delas é a do professor fazer o seu próprio material e outra por parte do aluno, que fica com um conteúdo repetido, porque, muitas vezes, os professores não têm tempo para a confecção de novos materiais para o dia seguinte.

Uma das principais dificuldades encontradas pelos professores está no ensino do Kaingang, onde não resta outra alternativa a não ser as dinâmicas em salas de aula, pelo fato de muitos alunos não falarem o Kaingang. Essa é uma dificuldade que ainda não se tem alternativa para ensinar com segurança o idioma.

Para os professores e direção da escola de ensino fundamental, tentar compreender os alunos individualmente parece ser impossível, pois cada um tem suas dificuldades de aprender a língua materna. Como ajudá-los a superar essa dificuldade sem material didático? Para trabalhar com esses alunos, os professores da escola contam apenas com um dicionário bilíngue, este elaborado em 2002 pela professora alemã Ursula Gojtéj Wiesemann.

O dicionário é trabalhado da educação infantil ao $9^{\circ}$ ano. Por esse e outros motivos que justificamos a necessidade desta reflexão, destacando as principais causas que dificultam o processo ensino-aprendizagem do povo kaingang.

A pesquisa foi realizada na comunidade indígena de Nonoai (RS), juntamente com a escola que atende os membros da comunidade sede. A importância da língua materna é mostrar que não é só uma forma de comunicação entre membros da comunidade, é entender como vive este povo e suas transformações, como aconteceu com o passar do tempo ou em diferentes temporalidades. 


\section{Os Kaingang - Educação formal e informal}

A tradição oral é muito importante para o povo kaingang. As pessoas mais velhas contam a história de sua vida e de seu povo para as crianças e para os jovens na Língua Kaingang. Assim, desde pequenas elas aprendem a língua e sobre a vida da família e do seu povo. Hoje, quando os avós não estão por perto, convém escrever esses saberes. O povo kaingang está registrando a sua história e o seu modo de ser.

Os índios da comunidade de Nonoai (RS) sofreram uma grande transformação no decorrer dos últimos anos desse iniciar do século XXI. A maioria das crianças indígenas aprendeu a língua materna junto com seus familiares e quando atingem a idade escolar são alfabetizados em Kaingang, sendo que aprendem a valorização dos costumes, das comidas típicas, das crenças e tradições que são passados de pai para filho e que vêm de várias gerações.

Segundo os pais e os sábios da comunidade indígena, a Língua Kaingang, administrada como ensino bilíngue, deve ser iniciada ainda na educação infantil, dando prosseguimento à fala das crianças, contextualizada e historicizada na cultura e não com palavras isoladas como foi a prática de muitos anos, adotada pelo governo por meio de seus órgão institucionalizados.

Por isso, a escola indígena de Nonoai pode ser considerada como praticante de uma educação diferenciada, pensada com o planejamento da comunidade indígena, pois os próprios professores prepararam os conteúdos de aula. Percebemos aqui a importância de se formar educadores da própria comunidade, ou seja, professores da etnia, não desconsiderando a presença e importância dos demais professores no processo ensino-aprendizagem. 
Destacamos na escola a importância de professores que conhecerem as tradições, a cultura e que ajudam no desenvolvimento sociocultural e humano da comunidade.

Concordamos com Piovezana et al. (2007, p. 116) quando afirmam que “[...] entre as metodologias para aprender a língua materna utiliza-se o recurso do desenho, da paisagem, do conhecido da criança, porque se percebeu que esses recursos facilitam e aprofundam a relação ensino aprendizagem." Por isso, estabeleceu-se um modelo pedagógico diferenciado, baseado na maneira de como as crianças (índios) veem o mundo não índio e o uso do idioma materno. Esses processos de aprendizagem são fundamentais para a escola indígena de Nonoai, pois esta pode usufruir da possibilidade de colocar em prática suas concepções próprias sobre o que deve ser ensinado, o que deve ser aprendido pelos aluno, quando planejado com o querer e formas de representações da comunidade.

Na comunidade indígena de Nonoai, a escola não é vista como um único lugar de ensinar as crianças, mas os mais velhos passam a sua sabedoria em forma de dança e palestra para os mais jovens.

Nas Terras Indígenas kaingang, mesmo nas aldeias com maior número de índios os princípios da educação informal [...] que envolvem tanto crianças quanto homens e mulheres que participam desde o nascimento e estão inseridos num mundo de aprendizado, estão no coletivo. (PIOVEZANA et al., 2007, p. 102).

O principal objetivo da escola indígena Nonoai é educar para a conquista da autonomia socioeconômica e cultural, trabalhando para a revitalização da memória dos seus antepassados e para a afirmação da identidade étnica, pela valorização da língua ma- 
terna e costumes tradicionais nas formas de educar as crianças e concomitante, se apropriarem dos conhecimentos acumulados pela humanidade e poder, também, contribuir para a construção de novos saberes e dignidade de vida.

De acordo com Piovezana et al. (2007, p. 116), “[...] para alcançar tais objetivos os professores devem criar metodologias específicas, próprias para aqueles que não falam o idioma kaingang, podendo assim aprender a língua." A escola indígena Nonoai não só ensina o Kaingang para os alunos, mas também outros conteúdos ministrados pelos componentes curriculares de Língua Portuguesa, Matemática, Artes, Educação Física, História, Língua Inglesa, Ciências, Ensino Religioso e Geografia. O ensino religioso trabalha na perspectiva de revitalizar a cultura, em estudos compartilhados com a História e a Geografia.

A escola indígena de Nonoai sofre com a falta de material didático-pedagógico para trabalhar com os alunos, contando somente com os livros didáticos distribuído aos alunos e com uma biblioteca precária e desatualizada. O problema mais grave está na falta de material didático e domínio de metodologias para o ensino da língua materna. Os professores elaboram com muita dificuldade o material para os alunos; desta forma, a produção do conhecimento está muito ligada a comunicação oral.

$\mathrm{Na}$ escola, consideram a Geografia como uma disciplina muito importante, porque estuda as fronteiras da Aldeia e seus limites, onde a dificuldade está em entender o território delimitado pelos brancos e sentidos de territorialidade. Estuda a geopolítica da comunidade, identidade, tradição, rios, climas, danças, língua, música e o mais importante considerado pela comunidade: o meio ambiente atrelado à realidade do povo. Com todas essas possibi- 
lidades, de certa forma trabalha a interdisciplinaridade, em que os professores participam com os alunos nos processos de aprendizagem, ainda que com dificuldades.

O processo de ensino nesse contexto tem como objetivo integrar as disciplinas a partir da elaboração de propostas que procurassem ao mesmo tempo vincular os conteúdos específicos por meio de temáticas e atender aos interesses dos alunos favorecendo o seu aprendizado e ampliando seu conhecimento. (REGO; CASTROGIOVANNI; KAERCHER, 2007, p. 60).

A escola indígena, no nosso entender, deve integrar as disciplinas, os alunos e os professores que trabalham na escola, índios e não índios. Mas para que isso aconteça, precisa produzir, criar temáticas interessantes, que todos os alunos possam participar e que ampliem seu conhecimento e sua valorização como membros da comunidade. As temáticas devem ser significativas e devem estar carregadas de representações e simbologias da comunidade (PIOVEZANA et al., 2007).

Não se pode esquecer que os momentos e atividades de ensino-aprendizagem combinam espaços e momentos formais e informais com concepções próprias sobre o que deve ser aprendido como, quando e por quem. A escola, neste sentido, não pode ser vista como o único lugar de aprendizado. A comunidade possui sabedoria para ser comunicada, transmitida e ensinada por seus membros [...]. (PIOVEZANA et al., 2007, p. 102).

A comunidade indígena de Nonoai utiliza na formação inicial para o processo ensino-aprendizagem a língua informal, aquela que a criança aprende com seus pais. Em casa não precisam ter 
normas ou saber falar corretamente, porque isso quem faz, dizem os pais, é a escola. Quando a criança chega à escola é ensinada lentamente a linguagem formal, observando as normas cultas do idioma. Devem pronunciar as palavras e escrevê-las corretamente. Muitos crianças e adolescentes falam, mas não sabem escrever e ler a sua própria língua, pois a oralidade dos mais velhos e a memória não necessitavam desses tipos de anotações. A fala do Kaingang diz muito e é carregada de memórias e significados e que não se conseguiu ainda traduzi-la nas linhas escritas, que, segundo os mais velhos dizem, perdeu o sentido.

\section{Planejamentos de Ensino - uma questão formal}

Compilamos os planejamentos para o ensino da Língua Portuguesa e Cultura Indígena, como exemplo da prática pedagógica formal na escola, nos anos iniciais do ensino fundamental.

Planejamento anual de Língua Portuguesa.

Primeiro e segundo anos das séries iniciais. Objetivo geral: compreender a Língua Portuguesa, como um código de comunicação, interpretação, produção, nas relações humanas no contexto social diário. Objetivos específicos: reconhecer a importância da comunicação; diferenciar linguagem verbal de linguagem não verbal; conhecer a influência dos diversos fatores na nossa língua; conhecer os níveis de linguagem; diferenciar neologismo e gíria; diferenciar fonologia, morfologia e sintaxe; conhecer a significação das palavras, diferenciando sinônimos e antônimos, homônimos e parônimo; reconhecer o sentido conotativo e denotativo e exercitá-lo; conhecer e diferenciar as funções de linguagem; 
diferenciar fonemas e letras; fazer a classificação dos fonemas; compreender a classificação das palavras quanto ao número de sílabas; diferenciar e compreender encontros vocálicos e consonantais; reconhecer ortografia conceituando-a; fazer a classificação das palavras quanto a sílaba tônica; diferenciar acento prosódico e acento gráfico; estudar as regras de acentuação gráfica; conhecer a estrutura das palavras; conhecer a formação das palavras; definir arte literária; compreender a função poética da linguagem; conhecer e diferenciar as figuras de linguagem e no que elas consistem; conhecer os gêneros literários diferenciando-os; compreender a força da palavra escrita; valorizar a expressividade da pontuação dentro do texto; conhecer novos vocábulos usando-os dentro dos textos produzidos; reconhecer os elementos da narração, descrição e dissertação; formular hipóteses sobre os textos abordados; comparar textos, estabelecendo relações intertextuais atualizadas; conscientização da importância da leitura como meio de aquisição de conhecimento e fonte de prazer.

Para o desenvolvimento dos objetivos propostos, são indicados os seguintes conteúdos: comunicação e Língua Portuguesa; significação das palavras; funções da linguagem; fonologia; sílaba; ortografia; acentuação; estrutura das palavras; formação das palavras. A arte literária; a função poética da linguagem; figuras de linguagem; os gêneros literários; trovadorismo português; redação básica. Projeto. (Música na escola).

Terceiro e quarto anos das séries iniciais. Objetivo geral: compreender a linguagem como um código de comunicação, interpretação e produção das relações humanas no contexto social indígena. Objetivos específicos: valorizar a cultura como a soma de todas as realizações das pessoas; conhecer as classes de palavras e 
identificá-las nas orações; identificar, diferenciar, flexionar e empregar todas as classes gramaticais em todos os tempos simples e composto; aplicar corretamente os verbos quanto à predicação e colocação pronominal em análises sintéticas; aplicar corretamente os elementos da estrutura de palavras; comparar e diferenciar com conhecimento, conto, crônica, romance e poesia; entender que o texto oral difere do texto escrito, e que no texto escrito a clareza e o fator essencial, uma vez que o leitor não está no momento da leitura; evidenciar seus enunciados que a língua oferece formas novas de expressão; analisar e elaborar textos críticos, desenvolvendo a criatividade, o pensamento crítico no processo de aprendizagem reconstituindo vários mundos reais ou imaginários; reconhecer diferentes estruturas linguísticas e manusear gramáticas e sua metalinguagem para resolver dúvidas relativas às formas de expressão da língua e da cultura; entender a obra literária como manifestação de determinada época cultural e sua vinculação intertextual e outras de manifestação artística literária ou não; pesquisar sobre os autores da literatura brasileira; saber digerir um bom texto; conhecer as funções de linguagem dentro do texto.

Os conteúdos propostos para os objetivos acima são: as classes das palavras; substantivo; adjetivo; artigo; pronome; numeral; verbo - estrutura e flexões; verbo - classificação e paradigmas de conjunção; as categorias gramaticais invariáveis: advérbio e preposição; as categorias gramaticais invariáveis: conjunção e interjeição; redação; poesia. Projeto.

Planejamento da disciplina de Cultura para o quinto ano do ensino fundamental.

Parte-se da temática "trabalho e cultura", com o objetivo geral de: mostrar as correlações existentes entre trabalho e cultura indí- 
gena: presente/passado/presente. Os conteúdos estão delimitados nas temáticas: os indígenas, primeiros povoadores do Brasil e do Rio grande do Sul. A ocupação do espaço territorial do Rio Grande do Sul: séculos XVII-XIX. As migrações e a formação histórica do Rio Grande do Sul e do Brasil: séculos XVIII-XIX. Campo, cidade e alterações da paisagem na história brasileira. Industrialização e desenvolvimento urbano no Rio Grande do Sul. Para o desenvolvimento são necessários habilidade e competências como: identificar as singularidade de diferentes contexto históricos. Comparar diferentes temporalidades, a partir de dados da realidade local e regional. Perceber as mudanças e permanências em diferentes épocas. Perceber as relações entre sociedade, cultura e natureza, em diferentes momentos da história.

O que apresentamos acima foi uma pequena amostra dos moldes da educação escolar indígena praticada na escola. Percebemos que obedece a um currículo preelaborado pela sociedade não indígena, mesmo que com algumas iniciativas de mudanças para contemplar a cultura indígena Kaingang. Nosso objetivo é que possamos fazer a leitura da educação formal e não formal a que nos referimos.

Analisamos ainda que nos demais anos ou séries escolares da comunidade indígena de Nonoai, à medida que avançam, os conteúdos e metodologias de ensino vão se aprofundando mais nas questões relativas à cultura do povo kaingang. O problema está que quando estão mais atentos às questões comunitárias e cultural indígena, vão estudar em escolas fora da Aldeia, sem atendimento diferenciado. A maioria não retorna para a Aldeia depois de formados devido ao trabalho ou outras oportunidades de emprego ou de casamentos. 


\section{Educação familiar indígena}

Todos os membros da família Kaingang têm responsabilidade pelas crianças. A mãe fica responsável até a criança estar mamando, depois disso o pai e os avós da criança começam a ensinar as coisas sobre os Kaingang. No primeiro momento a criança recebe uma atenção especial dos seus pais e avós sobre o seu comportamento diante da sociedade Kaingang, o que é errado e o que é certo.

Para os membros da terra indígena de Nonoai, as crianças aprendem observando e escutando as pessoas mais velhas. Elas acompanham as atividades da família e aprendem os conhecimentos sobre os saberes da cultura e da vida. Para alguns membros da comunidade indígena, os ensinamentos recebidos saíam de casa: lembro, como pertencente da comunidade, que nós ficávamos ao redor do fogo na aldeia escutando as histórias, recebendo conselhos dos mais velhos, aprendendo a respeito do amor pela natureza como mãe primeira e lições que motivavam o orgulho de ser Kaingang.

Quando falamos de educação indígena, podemos apontar para três pontos fundamentais: a) organização social dentro da comunidade indígena. b) os valores culturais. c) e as relações de trabalho. A interligação dos três pontos constitui a lógica da educação indígena. Dessa forma, o aprendizado da criança, do jovem ou de qualquer membro da comunidade vai se constituindo de maneira que não fique um conhecimento sem sentido ou sem valor. A educação está presente na família, ou seja, na convivência com todos os membros da comunidade que está presente, as crianças aprendem a viver em uma relação de parentesco e, assim, entendem as concepções de mundo construindo suas relações seja de trabalho ou de parentesco. Nesse trabalho será na mata buscar cipó, taquara e outros 
materiais para confeccionar seus artesanatos, enquanto outros ainda buscam remédios, as crianças estão presentes e o conhecimento dos mais velhos é passado a cada um que será reproduzido nos demais membros da família, constituindo todo o conhecimento do sistema de vivência, o comunitário. Os valores transmitido pelos mais velhos, pai, mãe jamais será esquecido. (FERREIRA, 2008, p. 175).

As crianças aprendem a respeitar tudo sobre a sociedade, os mais velhos, os seus tios, sobre as marcas e sobre as tradições da comunidade. Se a criança for um menino, a educação fica na responsabilidade do seu pai, juntamente com seu avô, que lhe ensina tudo o que seu pai lhe ensinou, como fazer um artesanato, a festa do Kiki, sobre a troca de um pajé, sobre uma reza no dia de um funeral. Ensina tudo sobre o casamento, como saber se a moça escolhida não é da mesma marca que o rapaz, isso fica a cargo do avô. Essa é a educação indígena, na qual é passado de avô e pai para o filho. Tudo isso é ensinado em casa, na família, educação que os pais passam para os filhos antes de chegar à escola.

A ajuda dos pais é importante, pois é por meio dela que conseguimos transmitir os conhecimentos do nosso povo Kaingang e, ao mesmo tempo, aprendemos com as informações que eles ensinam em casa. Os pais auxiliam a escola nos dias de festas com artesanatos nas reuniões, quando dizemos que está bom ou que precisa melhorar na escola e no ensino. (FREITA, 2008, p. 25).

Segundo alguns Kaingang, a educação se dá não só na família ou na escola, mas em todos os lugares da comunidade, até no campo de futebol. Também se dá nas reuniões que o cacique, juntamente com suas lideranças, fala sobre a cultura, os antepassados, o cultivo de plantas e como plantavam para a sobrevivência de suas 
famílias. Para os mais velhos e os antigos indígenas, o dinheiro não tinha valor nenhum e o que mais queriam era viver em paz com a natureza.

Quando o aluno chega à escola, depara-se com um mundo novo. $\mathrm{O}$ correto é que essa criança seja alfabetizada em kaingang e a partir da $3^{\text {a }}$ série, quando o professor vai começar o ensino da Língua Portuguesa. Nessa fase é o professor que vai trabalhar os valores culturais da comunidade, aí que a criança vai saber o porquê das marcas, das danças, comidas típicas e outros costumes que são passados em forma de palestra e apresentações culturais.

A educação indígena não se dá somente por meio de livros didáticos, mas também em todos os lugares da comunidade, no campo de futebol, ma igreja, em casa. $\mathrm{Na}$ escola trabalhamos com os remédios naturais, comidas típicas, artesanatos a língua materna, costumes e crenças. O educador deve ter consciência que tem uma missão a cumprir: a de conscientizar os alunos sobre a importância de tem o resgate de sua cultura dentro da comunidade e da sociedade. Durante esses processos as crianças e jovens passam a compreender e valorizar a importância dos mais velhos ou até mesmo das folhagem que fazem parte da culinária ou medicina Kaingang. (FREITA, 2008, p. 28).

Alguns aspectos se devem observar na cultura Kaingang, como a dança, em que só pode dançar se o menino é de uma marca e a menina for de outra. Caso o menino seja da marca bolinha, só pode dançar com uma menina que for da marca do risquinho. Quem faz isso é o professor, juntamente com os pais. Na escola os alunos aprendem tudo sobre os antepassados. Os mais velhos contribuem com seus conhecimentos, suas histórias, suas lendas, suas vivências na comunidade. Quando um professor trata de um desses assuntos, os alunos são levados e acompanhados até a casa 
de um índio mais velho que irá falar sobre os mitos, as lendas e os costumes. Esse trabalho é realizado ou pelo menos planejado para realizar concomitante aos conteúdos obrigatórios do ensino fundamental, pois os Kaingang vivem hoje em pequenas aldeias, terras indígenas (reservas), cercados pela sociedade não indígena.

A educação indígena leva em conta três pontos básicos: a organização social dentro da comunidade indígena; a questão dos valores culturais; e a relação de trabalho. Esses pontos se interligam dando suporte para a construção do conhecimento de cada comunidade indígena. Por outro lado, temos a educação formal ou oficial que introduz nas comunidades indígenas novos valores que modificam as formas de agir e perceber o mundo Kaingang e que prevalece na realidade pela falta de preparo e de conhecimentos específicos da cultura.

Hoje infelizmente, se perdeu muito culturalmente. Inúmeras crianças não conhecerem o significado de várias manifestações da cultura Kaingang, que são essenciais no seu meio social ou para que se dê continuidade à herança cultural. Portanto por meio da revitalização (do resgate) de sua própria história, crenças e tradições, a comunidade escolar se reconhece como parte integrante dos mesmos, podendo assim desenvolver práticas educacionais que venham preservar e recuperar sua história. (EMÍLIO, 2008).

Porém, importante é dizer que, quando falamos de educação indígena, devemos lembrar que cada povo tem seus modos próprios de aprendizado, levando em conta que geralmente os Kaingang aprendem com os mais velhos e com os modelos existentes na sua cultura. 


\section{Terra indígena Nonoai}

O 'grande aldeamento' de Nonoai foi demarcado em 1856, tendo como limites os Rio Uruguai, Passo Fundo e Rio da Várzea. A Área foi invadida aos pouco e redemarcada no início do século XX, reduzida, então, a uma pequeníssima fração do que fora antes. (RAMOS, 2006, p. 41).

O espaço físico geográfico destinado aos índios da reserva indígena de Nonoai, conhecida como "Toldo Nonoai”, foi demarcada pela diretoria de terras e colonização da Secretaria de Viação e Obras Públicas do estado do Rio Grande do Sul, com a área total de 34.908 hectares, resultando na elaboração de um mapa onde consta o perímetro, limites e confrontação, cuja matriz encontra-se arquivada no Setor de Terras Públicas do estado, junto a Secretaria da Agricultura.

O governo da província do Rio Grande do Sul chegou a formular o projeto de um aldeamento único para os Kaingang, reunindo todos nos campos de Nonoai, e promovendo a extinção de outros aldeamentos. Isso pretendia limitar a área de ocupação indígena. Liberando a maioria das terras, e dando garantia aos fazendeiros de não se correr o risco de serem atacados pelos índios. Com o fim de garantir essa segurança aos invasores, foi criada uma campanha de pedestres (hierarquia militar) em 1847, em Nonoai, sob o comando do capitão Marcelino Carmo, com o objetivo de reter os índios no aldeamento único, que contava com a presença de mais de 800 Kaingang vindos das vizinhanças de Passo Fundo. (RAMOS, 2006, p. 41).

Em 1949, o então governador do estado, Walter Jobin, reduziu a área ocupada pelos índios, criando o Parque Florestal de Nonoai, com a área de 19.998 hectares, através do decreto estadual n. 
658, de 10 de março de 1949, em seu Art. 1 . São declaradas de utilidades públicas para fim espacial de constituírem reservas as terras de florestas abaixo discriminadas ainda de domínio do estado. Uma área de 19.998 hectares, junto ao Toldo Nonoai, no Distrito de Nonoai, município de Sarandi, com as seguintes confrontações. SUL: terras devolutas do Toldo Nonoai. LESTE: toldo de Nonoai. OESTE: terras devolutas do loteado Demétrio e rio da Várzea do decreto estadual n. 13.795, de 10 de julho de 1962, que alterou o decreto 658, alterando as confrontações do Art. $1^{\circ}$. A Reserva Florestal de Nonoai, demarcada pelo decreto 658, de 10 de março de 1949, passa a ter os seguintes limites. NORTE: pela estrada geral de Nonoai a planalto com o toldo de Nonoai. SUL: por linhas seca com a $1^{\circ}$ secção de Pinhalzinho, com terras do estado demarcadas com a posse de Cirino Velozo Linhares. OESTE: por linha seca com terras desmembradas da mesma área e por linha seca com terras em demarcação pelo estado, pelo arroio Demétrio e pelo rio da Várzea.

O decreto 13.795 desmembrou a área original destinada ao parque, uma área de 2.499 hectares destinada à formação da $4^{\mathrm{a}}$ seção de Planalto, por meio de lotes entregues pelo estado a agricultores "sem terras". Depois de demarcada, brancos e índios ficaram proibidos de entrarem na área florestal para caçar, pecar, coletar frutas ou tirar qualquer coisa pertencente ao parque e para segurança foram colocados funcionários do estado, denominados como os "tais guardas florestais".

Muitos índios foram pegos por estes guardas, sendo que alguns ainda vivem. Muitos eram caçados no interior da floresta. Os guardas massacraram, humilhavam e surravam os índios, muitas vezes faziam com que estes comessem a caça e a pesca crua como castigo. Faziam comer os peixes e as minhocas cruas. 
A reserva, com 34,9 mil hectares, é dividida também entre Planalto, Nonoai e Gramado dos Loureiros. Na área residem três mil índios, em sua maioria da etnia Kaingang. Desses, duzentos são do povo guarani. Vivendo no local demarcado em 1911, cultivam costumes e tradições dos seus antepassados e recebem assistência médica e social da Fundação Nacional do Índio (FUNAI/SESAI).

A colonização por não indígenas na aldeia Nonoai teve início em 1912, com a implantação de uma serraria, ponto de partida para o povoamento e comercialização das Terras Indígenas da região de Nonoai (RS) e, consequentemente, com a implantação de muitas escolas no interior, para atender a demanda dos brancos e, posteriormente, de alguns indígenas.

\section{Escola Kaingang e educação indígena}

Falar da educação dos índios requer breve análise história deste povo. Precisamos reconhecer que, nesses 512 anos, os povos indígenas têm sido destruídos, mortos, perseguidos e marginalizados pelos "brancos civilizados”. Mesmo com toda política de proteção e leis, preocupadas pela qualidade de vida dos índios, estamos longe de um tratamento digno e justo àqueles que foram os primeiros habitantes desta terra. Se este é um povo que vem perdendo sua identidade, sua cultura e costumes, sua história e a própria vida, são consequências de tais políticas e descasos governamentais com nosso povo. Várias tribos foram dizimadas por doenças trazidas por matizes de europeus e a educação teve seu processo e seus propósitos de participação para tais conquistas.

De modo geral, a educação indígena antigamente tinha objetivo de catequizar os índios e torná-los missionários, apaziguando-os, 
tornando-os dóceis e submissos às necessidades de outras culturas e credos religiosos. Ensinavam a Língua Portuguesa, desconsideravam os mitos, as crenças, os hábitos indígenas e as aulas eram ministradas por professores brancos, primeiramente por padres católicos e posteriormente por pessoas comuns, que passavam a viver nas aldeias para educar, catequizar os indígenas.

Algumas tribos passaram a viver mais como brancos do que como índios, maravilhados pelas novidades e comodidades da vida fora da aldeia. Outros foram incansáveis e defenderam a cultura, costumes e modo de vida dos Kaingang. Devido à realidade de exploração que a maioria das tribos vivia, os próprios povos sentiram a necessidade de aprender a escrita de sua língua como uma forma de preservar e assegurar para as gerações futuras, mesmo que nos moldes dos ensinamentos dos "brancos".

Até a década de 1970, as comunidades indígenas não tinham escolas, a educação era a familiar tradicional, em que eram os velhos que passavam o seu conhecimento de forma oral e simbólica, associada à sociocosmologia. Esse conhecimento era passado de avô para neto, cujo dever era o de passar para a próxima geração.

Quando as escolas oficiais do estado entraram nas aldeias indígenas tinham como dever ensinar a Língua Portuguesa, não considerando a língua materna. Além da precariedade dos espaços para administrar as aulas, os professores não eram bilíngues e dificilmente ocorria o processo de alfabetização, causando muita evasão escolar. Outro problema era a falta de professores, profissionais indígenas para trabalhar como educadores bilíngues.

$\mathrm{Na}$ década de 1980, poucos indígenas frequentavam a escola, pois esta era vista como uma coisa ruim para a comunidade. $\mathrm{Na}$ escola da comunidade, que se chamava Marechal Cândido Rondon, duas professoras trabalhavam com as quatro turmas e também 
como domésticas e serventes, onde faziam e serviam a merenda para os alunos. A escola não possuía espaço suficiente, contava apenas com duas salas pequenas e uma cozinha. Nessa época havia colégios para a educação dos jovens brancos, onde eventualmente podiam conviver e estudar alguns indígenas devido às atuações missionárias, criadas para catequeses (BITTENCOURT; SILVA, 2002).

$\mathrm{Na}$ década de 1990, a educação escolar indígena era fundamentada em ações práticas que vinham de décadas anteriores, nos moldes da educação de religiosos. Os povos indígenas começam a reconhecer sua história e passam a reivindicar direitos, entre eles a educação indígena específica e diferenciada.

Na década de 1990, a escola ainda era muito pequena para atender a demanda da comunidade indígena de Nonoai, sendo que, devido às reconquistas das terras, muitos índios retornam para seus espaços de origem. As escolas nas terras indígenas são revitalizadas em 1999 e começam a fazer parte dos sistemas de ensino do País. Essas escolas podem organizar seus próprios regimentos e calendários específicos, só que na realidade ainda são propósitos que estão apenas nos planos e no papel, pouco se tem conseguido fazer na prática e na realidade da comunidade indígena.

A escola indígena tem como objetivo manter os costumes dos índios, ensinar a partir da cultura e da sua língua materna. O currículo diferenciado não está apenas no ensino da língua materna, mas no processo ensino-aprendizagem de todos os componentes curriculares.

A educação indígena é composta por escolas diferenciadas que trabalham com o objetivo de não perder a cultura e principalmente ensinar a prática da língua para seus alunos. A presença de uma 
escola na comunidade indígena dá aos seus habitantes um sentimento de dignidade e respeito. O orgulho de possuir uma educação na própria comunidade é tão forte que mesmo que haja algum problema, com alguma coisa, não se vê ninguém falando em fechar a escolas. A comunidade já se deu conta que o idioma, que se emprega em forma escrita como meio de instrução e expressão, se desenvolve num orgulho autêntico, pois se vê respeitado e estudado como outras línguas.

A luta é pela escola bilíngue na comunidade, que permita à criança permanecer próximo de sua residência, aprendendo e evitando os traumas de um abandono forçado da língua e cultura indígena, porém, ao mesmo tempo, sabem que cada vez mais as crianças e comunidade vão se familiarizando com o idioma dominante.

Nesse processo, mesmo que com dificuldades, os alunos vêm adquirindo admiração pela sua língua e cultura indígena e também pelos costumes e cultura da sociedade nacional. Sentem-se satisfeitos por pertencerem a ambas as culturas.

Constatamos que é mais fácil às crianças indígenas começarem a aprender com um professor indígena, sendo alfabetizados na sua língua materna, para depois, familiarizados com a segunda língua, aprenderem a Língua Portuguesa, já falado na comunidade.

\section{Escola Estadual Indígena de Ensino Fundamental Joaquim Gatem Cassemiro}

A Escola Estadual Indígena de Ensino Fundamental Joaquim Gatem Cassemiro está situada a sete quilômetros da cidade de No- 
noai (RS), na terra indígena (sede), e fica ao sul do município de Nonoai. A estrutura física da escola em 2012 estava disposta em cinco salas de aula, um refeitório, uma cozinha, uma secretaria, uma biblioteca e uma horta com os cuidados do clube da árvore. Nesse clube da árvore, são trabalhado com os alunos da $5^{\text {a }}$ série e já rendeu um prêmio por incentivo aos cuidados com a natureza e com o meio ambiente.

Na horta são cultivados todos os tipos de verduras, utilizadas na própria alimentação dos alunos e também vendidas para a comunidade. A escola atende duzentos alunos de educação infantil ao $9^{\circ}$ ano do ensino fundamental.

A escola possui 14 professores, dos quais sete são indígenas. Três deles trabalham somente na educação infantil. Os outros quatro trabalham do $5^{\circ}$ ao $9^{\circ}$ anos, sendo que um só trabalha com a língua materna e, este professor, é habilitado como bilíngue. Este trabalha com os costumes, comida, tradição, dança e o mais importante é que esse professor trabalha na alfabetização dos alunos da $2^{\text {a }}$ série. Ele é o responsável pelo grupo de dança da escola e de pesquisas, juntamente com uma pessoa mais velha da comunidade, sendo que essa pessoa passa toda a sua sabedoria para os mais novos, que são alunos na escola da comunidade. Os outros quatro professores índios que trabalham na escola ensinam Língua Portuguesa, Educação Física, Geografia e História. Esses professores já são formados em áreas específicas de trabalho e podem desenvolver um bom trabalho com seus alunos, porque conhecem bem a realidade de cada um deles. 


\section{Educação escolar ou educação indígena}

A Educação escolar indígena tem uma longa história, mas mais longa ainda é a educação indígena. Desde o início da colonização, a educação indígena passou por muitos transformações, fazendo frente à alfabetização e a educação escolar, que tiveram um papel importante nas relações. Jesuítas se esmeravam na catequese dos povos indígena, preparando gramáticas na língua dos índios e encerrando as crianças ou os jovens em seminários de diversas ordens religiosas católicas. Eles montaram suas escolas para os índios, sem dizer que o estado laico também atuou desde o império na educação dos indígenas. Ainda hoje, missionários evangélicos atuam em uma boa parte do território brasileiro, em projeto de alfabetização escolar e grafia das línguas indígenas. Com a intenção de salvar almas. (FERREIRA, 2008, p. 173).

A educação indígena, como um todo, vem sofrendo ao longo do tempo com a falta de material didático para se trabalhar com as crianças, com o pouco domínio dos pais frente as inovações tecnológicas e mesmo de questões sociais inclusas nas terras indígenas e fora delas, somando à falta de professores habilitados e que trabalhem a educação diferenciada. Na escola indígena de Nonoai não é diferente, a falta de material está preocupando os professores desta escola. Não se pode dar uma aula de qualidade sem material adequado para os alunos estudarem de forma diferente, a não ser a tradução de palavras e de textos. Os únicos materiais que a escola possui são: uma bíblia, um dicionário da Língua Portuguesa e Kaingang. São os únicos instrumentos disponíveis no momento para se trabalhar com os alunos indígenas.

Quando se trata de educação escolar indígena, percebemos que ao longo do tempo, tivemos uma educação baseada 
na integração das sociedade indígenas na comunidade nacional. Para fazer frente a esse projeto integracionista, oficial os movimentos indígenas, na década de 1970, começaram a se mobilizar e propor uma nova educação escolar, com participação ativa nas decisões, que mais tarde é reconhecida na constituição nacional de 1988 e a legislação específica que segue. Assim, configura-se uma política do estado os índios, como cidadão, passaram a ter direito a uma educação escolar. Nesse sentido, cria-se o que chamamos de educação específica e diferenciada, conquistando-se a garantia do direito ao respeito da sua cultura, língua e processos próprios de aprendizado. (FERREIRA, 2008, p. 174).

A Escola Estadual Indígena de Ensino Fundamental Joaquim Gatem Cassemiro atende exclusivamente a criança indígena, inclusive com alfabetização na língua materna (kaingang). A escola trabalha, juntamente com a coordenadoria regional de educação, para que se tenha um calendário diferenciado para atender, na medida do possível, as especificidades da comunidade. $\mathrm{O}$ ano letivo inicia na segunda quinzena de março e termina no início de dezembro, porque tem muitos alunos que saem nesse período de férias para vender artesanato. Também, a escola trabalha com tema pedagógico gerado dentro da comunidade, podendo o professor utilizar música, pesquisa, artes e a busca da valorização da cultura kaingang.

De acordo com Ferreira (2008), a escola diferenciada deve produzir a interculturalidade e o diálogo entre as culturas. Para que isso aconteça na prática, devem-se formar professores e educadores indígenas que os torne capazes de construir currículos pedagógicos e gerir as escolas indígenas e a formação de pesquisadores, ou seja, a capacidade para construir um currículo diferenciado, é uma possibilidade legal, assim o novo modelo escolar tem 
que permitir aos indígenas a posse das salas de aula e a construção de seu modelo pedagógico.

A escola está fazendo esse trabalho com o objetivo de ajudar o aluno a escrever corretamente na Língua Kaingang, podendo ele fazer diversos gêneros de texto para que posteriormente possa escrever com a mesma habilidade da Língua Portuguesa. O cuidado com a educação indígena é central, garantindo que a escola tenha vários professores indígenas, mas também não indígenas, para que haja assim a interação social e necessária como povo brasileiro. Os professores que são alfabetizadores na língua materna são todos índios. Por isso, tem uma facilidade de ensinar as crianças indígenas que frequentam a escola da comunidade.

A educação bilíngüe, adequada às peculiaridade culturais dos diferentes grupos, é melhor atendida de professores índios. É preciso reconhecer que a formação inicial e continuada dos própriosíndios, enquanto professores de suas comunidades, deve ocorre em serviço e concomitantemente à sua própria escolariza. A formação que se contempla deve capacitar os professores para a elaboração de currículos programas específicos para as escolas indígenas; 0 ensino bilíngüe, no que se refere à metodologia e ensino de segundas línguas e ao estabelecimento e uso de um sistema ortográfico das línguas maternas; a condução de pesquisa de caráter antropológico visando à sistematização incorporação dos conhecimento e saberes tradicionais das sociedades indígenas e à elaboração de materiais didáticopedagógicos, bilíngües ou não nas escolas instaladas em suas comunidades. (BRASIL, 2002, p. 31).

A grande dificuldade não está na fala, pois a Língua Kaingang possui entre suas características culturas a tradição oral, como sendo de máxima importância para a manutenção e transmissão de sua cultura. No entanto, é na escrita que o kaingang sente a dificul- 
dade, é nesse contexto que a escola aparece como facilitadora da aprendizagem, usando várias metodologias que o professor possa atingir os seus objetivos propostos. No início do ano juntam-se todos os professores que irão trabalhar com as séries iniciais, ou seja, do pré-escolar até a $4^{\text {a }}$ série. Esses professores se reúnem para discutir o que vai se trabalhar durante o trimestre. Os momentos de trabalho coletivo, porém, não se limitam às reuniões, é um trabalho contínuo, embora se fortaleça nas reuniões semanais e nas atividades mensais, em que se trabalha na elaboração de material para as atividades pedagógicas a serem desenvolvidas com os alunos em sala de aula.

O projeto de educação da escola Joaquim Gatem Cassemiro está voltado para o futuro da comunidade, em que as crianças aprendem a valorização da língua e da cultura indígena, reavivando o interesse dos jovens Kaingang pelas próprias histórias, danças, artesanato, língua, vida social e cultural da comunidade. Uma das formas de valorização das línguas indígenas vem sendo o processo de construção da escrita dessas línguas, sendo que esta missão está nas mãos dos professores que trabalham com as crianças indígenas. Ensinar os alunos como desenvolver a escrita em sua própria língua é uma tarefa árdua, mas compensatória e necessária. Antes a comunidade não considerava muito importante o estudo da língua materna. Por isso, foi criada uma forma de se organizar diferente das escolas do não índio.

Coloco aqui minha experiência pessoal. Estou com dificuldade para ensinar os alunos, pensei duas vezes, resolvi ensinar primeiro na Língua Portuguesa, depois na língua materna. Juntamos as letras e formamos nomes, como bola, pato e nomes de bicho. Eles(as) começaram a entender melhor as letras escritas e a entender a língua 
materna. Por este motivo é que muitos professores ensinam primeiramente a Língua Portuguesa. Logo que eles(as) começarem a ler, aí é que o professor vai lhes ensinar a língua materna (depoimento de um professor indígena). Contradiz com a literatura convencional, de que primeiro se deve aprender com a língua materna.

De acordo com Piovezana et al. (2007), a educação também é, ou pode ser, espaço de transformação de vida social e, por consequência, das próprias relações de produção. Ao mesmo tempo que é modificada pelo mundo da produção, ela também é capaz de modificá-lo. Importa, pois, redimensionar a ação educativa dentro do cenário sócio-político-econômico, fazendo com que o espaço educacional estabeleça relações concretas com o processo social; que leva a repensar o processo educativo para o sujeito, condições de compreender o meio em que está inserido. Para a comunidade indígena de Nonoai não é diferente.

A escola é o local onde os alunos passam quatro das 24 horas do dia. A escola é um ponto de referência para todos os que moram na comunidade. Conforme Piovezana et al. (2007), todas as comunidade indígenas dispõem de seus próprios processos de socialização e de formação das pessoas. Faz-se necessário também, para alguns grupos indígenas, a presença de pessoas que atuem na área educacional, incluindo neste processo os agentes educacionais. A presença de pessoas indígenas em qualquer área sempre é muito importante para os índios, pois as pessoas se sentem mais segura para falar um com o outro, e isso acontece muito na escola, principalmente na secretaria, em que trabalham com pessoas que não falam em Kaingang.

Para as pessoas mais velhas, fica mais difícil para se comunicar, por isso que na secretaria da escola Joaquim Gatem Cassemiro, da 
aldeia indígena de Nonoai, sempre tem uma pessoa que fala em Kaingang, para facilitar o trabalho das pessoas que ali trabalham e não falam o idioma indígena. Na escola, o Kaingang é utilizado como língua de instrução em diversas disciplinas. Na Matemática, Língua Portuguesa, Ciências, História, Geografia, além de se usar a Língua Kaingang, há também o resgate da cultura por meio da utilização de materiais extraídos da natureza, tais como ervas, sementes, pedras, a história que os antepassado contam para os mais jovens, entre outros.

Para um professor trabalhar a educação intercultural, deve ter a clareza de que cultura é toda a construção humana, o saber, o fazer, o ser de cada grupo impregnado de seus valores e significados conferidos às suas ações. A cultura é um eterno saber da sociedade Kaingang, e acumulando em si o que é adquirido, conservando e transmitindo entre as gerações todo o seu saber que possa ajudar a comunidade no futuro.

A cultura é para nós o que a água é para os peixe. E na cultura que se geram a consciência e o pensamento, nós somos gerado pela nossa cultura que geram a consciência e o pensamento. Nós somos paridos pela cultura, vivemos dentro dela e ela é o ambiente humano nosso se ela a nossa comunidade não existia nem nosso passado não teria. (MORADOR DA COMUNIDADE INDÍGENA DE NONOAI).

A cultura é, portanto, constitutiva do ser humano é um processo que ainda está se realizado. É na imensa diversidade e plasticidade das construções culturais que acontece a ligação do homem com a cultura. E o papel fundamental da escola é a valorização, o reconhecimento e o respeito à interculturalidade. 
A educação que queremos deverá futuramente ser o ensino primeiro e universal, centrado na condição humana. Os seres humanos devem reconhecer-se em sua humanidade comum e ao mesmo tempo reconhecer a diversidade cultural inerente a tudo que é humano. (MORIN, 2000, p. 47).

A educação intercultural permite ao aluno lidar com a diferença de modo positivo na vida, desmontado preconceitos e o papel da escola é o de ensinar a viver com o outro que não seja da comunidade, podendo ser índio de outra aldeia ou até mesmo não índio. Por esse motivo, a escola trabalha com o diálogo de aprender a conviver, vivenciando a própria cultura e respeitando as diferentes formas de expressão. Para os professores, o trabalho com diálogo com as crianças é muito importante para a vivência das crianças e dos jovens Kaingang.

Para a comunidade indígena de Nonoai, a língua materna é muito importante para a vivência do povo e para a comunicação, sendo que as lideranças também têm seu papel na aprendizagem do aluno.

\section{Entrevista com o povo Kaingang da TI Nonoai}

Primeiramente, como pesquisador e indígena, a entrevista que apresento foi realizada informalmente e num diálogo fraternal. Dos pais entrevistados, todos eles têm nome em Kaingang e eles sabem os seus significados. Esse nome foi escolhido pela pessoa mais velha da comunidade, o chamado cuiã. Este é o responsável pelo nome e pelo ritual do batismo.

As famílias que vivem na comunidade indígena de Nonoai (RS) têm em média cinco filhos na escola do pré-escolar ao $9^{\circ}$ ano, 
sendo que estes estão sendo alfabetizados em Kaingang e na Língua Portuguesa.

A renda mensal familiar é na média um salário mínimo e complementam com a confecção de artesanatos, que dá um extra, que assegura a sobrevivência dessas pessoas.

Todas as famílias que foram entrevistadas plantam uma lavoura de subsistência, cultivando feijão, milho, mandioca e batata doce, principalmente.

$\mathrm{O}$ artesanato é feito de vários tipos, dos mais simples até os mais sofisticados, como pinheirinhos para o Natal, anjos, bolas, fruteiras, arcos, lanças, peneiras, entre outros.

As famílias moram, segundo dados da entrevista, no geral de 4 a 53 anos, na comunidade de Nonoai. Viram acontecer muitas coisas boas e muitas coisas ruins também.

Aproximadamente $50 \%$ das famílias que foram entrevistadas sabem falar e escrever em Kaingang. As demais só falam em Kaingang. Apenas 5\% das pessoas entrevistadas não falam e nem escrevem em Kaingang.

Quanto às migrações, apenas uma família morou fora da aldeia, convivendo com a sociedade não indígena. As demais nunca moraram fora da aldeia. Segundo eles, são como um peixe fora da água, não conseguindo viver fora da aldeia, pois a vida deles está na aldeia de Nonoai (RS).

Todos os entrevistados gostam de morar na comunidade e justificam que é por causa da liberdade que dão para os filhos, toda a liberdade do mundo e essa não tem a violência da grande cidade. Outro motivo é a cultura do povo, dos antepassados, da história deles, que, no meu ver, é muito bonita.

As pessoas entrevistadas dizem que educam seus filhos com uma boa conversa e conselhos. Quando é menino, são os pais que 
têm esse papel. Quando é menina, a mãe é que tem a responsabilidade para educar a filha.

Os pais que foram entrevistados responderam que seus trabalhos não dependem da cidade, mas precisam dela para vender os seus artesanatos. Todos os pais dizem ensinar os seus filhos sobre as marcas, com conversas, ensinado-lhes a respeitar os parentes mais próximos e os de mais longe também.

Quando perguntados se gostam ou não de morar na TI Nonoai, todas as famílias responderam que gostam de morar na comunidade por se identificarem com a natureza e com a cultura do seu povo.

\section{Considerações finais}

O presente estudo resultou também de estudos realizados por pessoa não indígena, mas preocupados com os processos de condução e de atendimentos aos povos que foram pioneiros na ocupação desses espaços.

Por muitos anos, os povos habitantes das terras que chamamos hoje de Brasil foram os responsáveis pelos trabalhos de exploração e pagaram a custa de sangue o então progresso da nação. Tão logo esses recursos naturais vão se tornando escassos, já dizimados pelas guerras, pela fome, pela escravidão e, se não bastasse, pela caça e pelos genocídios incontáveis. Não queremos ser vítimas apenas, queremos ser reconhecidos como povo de luta e de garra, que são as razões de nossa sobrevivência, ainda que minorias.

Nossos pais, traídos, enganados e subjugados por todos os bárbaros europeus das Américas, souberam guardar o pouco que nos 
resta de nossas culturas, de nossa educação e do nosso respeito à vida e à natureza.

Distantes dos processos de educação formal, a condução era dada pela escola não indígena, com órgão governamental compostos por pessoas de outras etnias e que atendiam apenas aos interesses das classes dominantes, impregnadas de racismo e preconceitos, com interesses de acumular bens a qualquer custo, e para nós custos de vidas humanas.

Nas escolas, os professores não eram kaingang e até o ano de 1995 tínhamos que aprender seguindo seus modelos e processos de exclusões. Era impossível pretender conhecer e mesmo querer. A própria palavra "reserva” dizia para que estávamos lá.

Então, concluindo este estudo, nós, povos Kaingang, temos que recomeçar uma história educacional. Fomos preparados para fazer o mesmo e a educação diferenciada, muitas vezes, é um paliativo, uma mentira. Precisamos antes nos reencontrar, nos reconhecermos como povo, como nação, com nossos territórios e territorialidades.

Acreditamos no poder do conhecimento e que, a partir dele, de nossas crianças, possamos marcar presença nos espaços da sociedade brasileira como verdadeiros cidadãos de deveres e de direitos.

\section{Referências}

RACY, Lopes da Silva; BENZI, Luis Donisete Grupioni (Org.). A Temática Indígena na Escola. 2. ed. São Paulo: Global, 1998.

BENZI, Luis Donisete Grupioni. Experiências e Desafios na Formação de Professores Indígenas no Brasil. 1. ed. Brasília: INEP, 2003. 
BITTENCOURT, C. M. F.; SILVA, A. C. da. Perspectivas históricas da educação indígena no Brasil. In: PRADO, M. Lígia; VIDAL, Diana. À margem dos 500 anos: reflexões irreverentes. São Paulo: Edusp, 2002.

BRASIL. MINISTÉRIO DA EDUCAÇÃO. Referencial Curricular Nacional Para as Escolas Indígenas, Mec/ Sef, Brasília, 1998.

MINISTÉRIO DO MEIO AMBIENTE. Dos recursos hídricos e da Amazônia Legal. Brasília: Programa Nacional de Educação Ambiental, 1997.

BRASIL. SECRETARIA DE EDUCAÇÃO FUNDAMENTAL E MÉDIO. Parâmetros curriculares nacionais: introdução a os parâmetros curriculares nacionais. Brasília: Secretaria de Educação; MEC/SEF, 2002.

Parâmetros curriculares nacionais: terceiros e quarto ciclos - apresentação dos temas transversais. Brasília: Secretaria de Educação; MEC/SEF, 1998.

CASCINO, Fábio. Educação ambiental: princípios, histórias de formação de professores. São Paulo: Senac, 2000.

CIMI. Com as próprias mãos: professores indígenas construindo a autonomia de suas escolas. Brasília: CIMI, 1992.

COMIN. O Tempo passa o Tempo Volta. Cartilha para a semana dos povos indígenas. [s.l.]: IECLB, 2001.

D’ANGELIS, Wilmar R. Propostas para a formação de professores indígenas no Brasil. 1. ed. Brasília: INEP, 2003.

; VEIGA, Juracilda. Leitura e escrita em escolas indígenas: encontro de educação indígena no $10^{\circ}$ COLE/1995. Campinas: Associação de Leitura do Brasil, 1997. 223 p.

; ___ Mônaco Viver Repartindo. Cartilha para a semana dos povos indígenas. [s.l.]: IECLB, 2002.

DIAS, Genebal do Freire. Educação ambiental: princípios e práticas. São Paulo: Gaia, 1993. 
. Educação ambiental: princípios, histórias e formação de professores. São Paulo: Senac, 2000.

EMÍLIO, Regina Goj-Téj. Educação Escolar Indígena. Escola Estadual Indígena de Ensino Fundamental Joaquim Gatem Cassemiro. Entrevista concedida a Fernando L. Luchetta. 2008.

FERREIRA, Bruno. Educação escolar ou educação indígena. In: TEDESCHI, L. A. et al. (Orgs.). Abordagens Intercultural. Santo Ângelo: Uri Campus Santo Ângelo; Porto Alegre: Marins Livreiro, 2008.

. Rio Grande do Sul: tentativa de aldeamento único em Nonoai. In: RAMOS, D. et al. (Orgs.). Diálogos interculturais: identidades indígenas na escola não indígena. 1. ed. Campinas: Curt Nimuendajú, 2007.

FREITA, Joel Ribeiro. Professor da Escola Estadual Indígena de Ensino Fundamental Joaquim Gatem Cassemiro. Entrevista concedida a Fernando L. Luchetta. 2008.

HALL, Stuart. A Identidade Cultural na Pós Modernidade. 10. ed. Rio de Janeiro: DPEA, 2005.

MORIN, Edgar. Os sete saberes necessários à Educação do Futuro. 2. ed. São Paulo: Cortez, 2000.

NÖTZOLD, Ana Lúcia Vulfe. Nosso vizinho Kaingáng. Florianopólis: UFSC, 2003.

O ciclo de vida Kaingáng. Florianopólis: UFSC, 2004.

PIOVEZANA, Leonel; KACKE, Aneliese; RENK, Arlene; BLOEMER, Neusa Maria Sens. Os kaingang no oeste catarinense. 1. ed. Chapecó: Argos, 2007.

RAMOS, Antonio Dari. Diálogos Interculturais: identidades indígenas na escola não indígena. Campinas: Curt Nimuendajú, 2006.

REGO, Nelson; CASTROGIOVANNI, Antonio Carlos; KAERCHER, Nestor André. Geografia. 1. ed. Porto Alegre: Artmed, 2007. 
REIGOTA, M. Meio ambiente e representação social. Rio de Janeiro: Cortez, 1994.

SANTA CATARINA. Parâmetros Curriculares Nacionais Indígenas: meio ambiente e saúde. Florianópolis: Secretaria da Educação; MEC/ SEF, 1997.

\section{Notas}

* Indígena Kaingang, pós-graduado do PROEJA da UFRGS, graduado em Geografia pela Unochapecó e professor da Escola Estadual Indígena de Ensino Fundamental Joaquim Gatem Cassemiro de Nonoai (RS).

${ }^{* *}$ Prof. Leonel Piovezana, doutor em Desenvolvimento Regional pela UNISC. Professor do Mestrado em Educação da Universidade Comunitária da Região de Chapecó (SC) e coordenador das Licenciaturas Intercultural Indígena Ensino superior Indígena. 
